\title{
CIVILIZAÇÃO OCIDENTAL, IDEOLOGIA COLONIAL E FASCISMO.
}

\author{
CIVILIZAÇÃO OCIDENTAL, IDEOLOGIA COLONIAL E FASCISMO.
}

\section{CIVILIZAÇÃO OCIDENTAL, IDEOLOGIA COLONIAL E FASCISMO.}

DOI: http://dx.doi.org/10.9771/gmed.v11i2.33953

\begin{abstract}
Gianni Fresu ${ }^{1}$
Resumo: O presente artigo apresenta algumas reflexões sobre o fascismo e seu significado no contexto dos embates hegemônicos que caracterizam a civilização ocidental. $O$ fascismo se apresenta como o produto histórico do colonialismo e do seu legado ideológico autoritário e racista de dominação. O fascismo resulta da opressão da liberdade individual a fim de intensificar a exploração e a expropriação do trabalho para a acumulação intensiva do capital. Ressaltam-se as características do fascismo das primeiras décadas do século XX e o seu reaparecimento no momento de crise orgânica do capitalismo como um dos recursos de intensificação da exploração dos trabalhadores.
\end{abstract}

Palavras chave: fascismo, ideologia, colonialismo, imperialismo.

Resumen: Este artículo presenta algunas reflexiones sobre el fascismo y su significado en el contexto de los enfrentamientos hegemónicos que caracterizan a la civilización occidental. El fascismo se presenta como el producto histórico del colonialismo y su legado ideológico autoritario y racista de dominación. El fascismo resulta de la opresión de la libertad individual para intensificar la explotación y la expropiación del trabajo por la acumulación intensiva de capital. Destacamos las características del fascismo de las primeras décadas del siglo XX y su reaparición en el momento de la crisis orgánica del capitalismo como uno de los recursos para intensificar la explotación de los trabajadores.

Palabras clave: fascismo, ideología, colonialismo, imperialismo.

Abstract: This article presents some reflections on fascism and its meaning in the context of the hegemonic brunt that characterize Western civilization. Fascism presents itself as the historical product of colonialism and its authoritarian and racist ideological legacy of domination. Fascism results from the oppression of individual freedom in order to intensify the exploitation and expropriation of labor for capital intensive accumulation. The characteristics of fascism of the first decades of the twentieth century and its reappearance at the moment of the organic crisis of capitalism are highlighted as one of the resources for intensifying the exploitation of workers.

Keywords: fascism, ideology, colonialism, imperialism.

O fascismo representa um grande buraco negro da civilidade ocidental, diante do qual muitos intelectuais não conseguem esconder o próprio embaraço ideológico. Nesse sentido, o esquema logico clássico da autodefesa ideológica na retorica liberal consiste em apresentar o fascismo como um fenômeno alheio à tradição burguesa e à civilização ocidental.

Ao invés de estudar as responsabilidades endógenas do colapso liberal diante da barbárie fascista, o revisionismo histórico tende a considerar essa tragédia uma consequência do fanatismo totalitário bolchevique, não o produto histórico do colonialismo e do seu legado ideológico autoritário e racista de dominação absoluta de uma civilidade (a ocidental) sobre as outras.

Domenico Losurdo dedicou muitos estudos à crítica do revisionismo histórico e à hagiografia do pensamento liberal, todavia, isso nunca significou desconhecer os méritos e os pontos de força dessa 
tradição filosófica, mas escolher o terreno real da história superando as multíplices remoções e transfigurações que caracterizaram a sua narração apologética. Nesse sentido ele muitas vezes utilizou uma chave de leitura bastante eficaz: «o sofisma de Talmon».

Talmon era um estudioso do segundo pós-guerra que condenou a democracia totalitária (que segundo ele ia de Rousseau a Stalin) contrapondo-lhe a tradição liberal que (sempre segundo ele) jamais recorreu à coerção e à violência. Caraterística desse sofisma seria a tendência a comparar o socialismo histórico não com os fatos reais do mundo que esse movimento queria superar, mas com as grandes declarações de princípios da tradição liberal. Da mesma forma, no terreno da filosofia política, quando os apologistas do liberalismo tratam de Marx cada discurso inevitavelmente desemboca fatalmente na avaliação dos horrores do comunismo, enquanto, quando falam de John Locke, Constant e Bentham eles descrevem apenas os grandes valores ideais das teorias deles, nunca falam das guerras, da escravidão, do domínio colonial, da exploração e da miséria de massa da maioria da população mundial que marcam a história da civilização burguesia.

Contrariamente a essa narração, as três nações consideradas o berço da civilidade liberal (Inglaterra, Holanda e EUA) foram protagonistas da mais criminal obra de opressão da liberdade individual e de extermínio da história da humanidade: o comercio dos e escravos. O exemplo histórico mais brutal e integral de desumanização e genocídio que o Ocidente impôs ao resto do mundo não aconteceu apesar do liberalismo, mas contando com o apoio sincero dos grandes nomes da intelectualidade liberal Smith, Calhoun, Lieber, Fletcher e o mesmo Locke (dono de escravos e acionista da Royal African Company). Os mesmos grandes pais da chamada "pátria da liberdade" Washington, Madison e Jefferson (todos donos de escravos) foram também responsáveis do primeiro antecedente histórico da solução final imposta às seis nações de nativos americanos pelo Congresso dos EUA. Não casualmente Hitler utilizou o exemplo da conquista do Oeste para legitimar a sua ideia de espaço vital, e se inspirou exatamente na epopeia do "far West" quando imaginou de reservar aos povos do leste europeu a mesma sorte das tribos de nativos exterminadas pelos colonos norte-americanos. O paradoxo maior do liberalismo, como sublinhou Losurdo, é que a escravidão não foi um fenômeno que sobreviveu como rastro do passado apesar das três grandes revoluções liberais, pelo contrário, essa pratica desumana encontrou a sua máxima expansão exatamente depois dessas grandes viradas históricas que por um lado afirmaram a universal dignidade humana, mas, por outro, limitaram esse atributo de humanidade só aos povos europeus².

Todavia, a longa história do colonialismo, a academia onde Ocidente experimentou tanto a ideologia quanto a prática da dominação absoluta de uma civilidade sobre as outras, fica totalmente omitida pelas principais interpretações históricas liberais do fascismo.

Segundo o maior filosofo idealista italiano, Benedetto Croce, o fascismo é uma fratura na linha de continuidade da civilidade europeia. Da mesma forma, o movimento de Mussolini não seria o produto de uma só classe social, a burguesia, nem se afirmou pela sustentação de uma classe específica, mas é o resultado da perda de consciência e da profunda crise moral provocada pela guerra. Croce recusava a tese segundo a qual o grande industrialismo tivesse promovido o movimento de Mussolini. Para ele, pelo contrário, a burguesia industrial foi a classe que mais sofreu com o totalitarismo econômico e, na realidade, entre as 
camadas do capitalismo bancário e industrial, o consenso em relação ao fascismo era muito limitado. ${ }^{3}$ Neste sentido o fascismo seria apenas uma doença repentina no interior de um organismo integro, a sociedade burguesa.

A crise moral não foi simplesmente um fato italiano, mas uma característica da maior parte dos países envolvidos na guerra mundial. O fascismo correspondia a um rebaixamento na consciência de liberdade depois do conflito. No contexto da história italiana, isso parecia a Croce um "parêntese" no processo de expansão do liberalismo oriundo da tradição do Risorgimento. A leitura de Croce tinha duas evidentes tarefas políticas: absolver o liberalismo italiano pelas graves responsabilidades na falta de oposição ao fascismo no momento do seu nascimento; favorecer a sua volta ao poder depois da queda do Mussolini. ${ }^{4}$

Esta concepção conheceu também uma variante alemã no livro $A$ catástrofe da Alemanha, de Friedrich Meinecke ${ }^{5}$. Ele interpretou o fascismo e o nacional-socialismo como um afastamento da linha evolutiva dos países europeus, uma crise moral provocada por dois fatores conjuntos: a mobilização das massas populares e a mudança na técnica e nos estilos de vida produzidos pela Segunda Revolução Industrial. Meinecke se liga ao historiador suíço Jacob Buckhardt ao localizar entre as ilusões do Iluminismo e da Revolução Francesa "o germe da grande doença” que teria debilitado moralmente - particularmente depois da industrialização e do advento da sociedade de massa - os povos europeus, gerando uma equivocada aspiração à felicidade (potência, riqueza e avidez de ganho). Para satisfazer esta felicidade econômica os povos estiveram dispostos a sacrificar a liberdade e submeter-se à disciplina e à obediência militar. A guerra teria facilitado a explosão desta crise (já em curso) numa orgia de irracionalidade, na qual grande parte dos valores morais da Europa foram deixados de lado em favor do desejo da vitória e de potência.

O ressentimento pela derrota e o espírito de resgate da dignidade diante das injustas condições impostas pelo Tratado de Versalhes, a crise econômica e o que ela produziu, tornaram frágeis todos os equilíbrios da sociedade, favorecendo, especialmente nas jovens gerações, os impulsos mais irracionais e niilistas em função da nova ética do egoísmo nacional. Neste delírio, cada exagero encontrava justificação se virtualmente capaz de aumentar a potência da nação e a riqueza da comunidade. Meineicke falava de "renascimento maquiavélico" e de transformação do maquiavelismo de fenômeno aristocrático em fenômeno burguês e de massa, ligado ao aumento da população mundial e da abstenção da cidadania ativa no plano político. ${ }^{6}$

Segundo Ernts Nolte 7 , a investigação sobre o fascismo teria que aprofundar as questões filosóficas para buscar entender a sua essência fundamental, deixando de fora os elementos secundários ou folclóricos do fenômeno. Para o máximo representante do revisionismo histórico europeu, o fascismo nasce sim no seio da sociedade liberal, mas não pode existir sem o desafio ao bolchevismo e ao marxismo em geral. A vitória da Revolução de Outubro e o nascimento de um forte movimento comunista organizado em nível internacional seriam então o elemento central sem o qual não é possível falar do fascismo. Portanto, a Revolução de 1917 seria o evento fundamental, o verdadeiro responsável pelo nascimento do fascismo, movimento surgido em defesa do Estado e da ordem social ameaçada pela subversão. Por sua vez, a Primeira Guerra Mundial seria a chave para compreender a afirmação seja do comunismo seja do fascismo. 
O antimarxismo e a luta política seriam um apêndice do conflito bélico que, entre 1914 e 1918, dividiu a Europa em duas frentes, os nacionalistas e as forças consideradas antinacionais. As manifestações de fanatismo, o espírito patriótico, o entusiasmo para a guerra, o ódio total perante o inimigo, que antecipam e seguem o início do conflito, são os motivos ideológicos e sentimentais essenciais do nascimento deste movimento.

Em todas essas leituras, que inevitavelmente acabam interpretando o fascismo e o comunismo como irmãos gêmeos do mesmo totalitarismo, o movimento de Mussolini seria o fruto do fanatismo ideológico desencadeado pela guerra e pela Revolução de outubro. Totalmente omitida é a conexão entre a natural propensão colonialista do capitalismo e as heranças ideológicas da mentalidade imperial nos fermentos radicais do nacionalismo que favoreceram o surgimento do fascismo. Limitar o estudo sobre as raízes do fascismo ao período entre 1914 e 1945 corresponde exatamente a essa necessidade ideológica. Pelo contrário, para compreender o fenômeno fascista (além da tradição colonial) é necessário enquadrá-lo historicamente, pois sem considerar as profundas mudanças que marcam a economia, a organização social e a política internacional entre o final do século XIX e a Primeira Guerra Mundial, torna-se difícil expor racionalmente o que este movimento tem representado.

As últimas quatro décadas do século XIX geralmente são definidas como a época da Segunda Revolução Industrial. Sem qualquer exagero determinista, tratou-se de um processo internacional que em pouco tempo transformou radicalmente sistemas de produções, relações sociais, dinâmicas políticas e também estilos de vidas. Estas mudanças produziram uma confiança sem limites no progresso industrial e científico, que contribuíram para que se afirmassem os mitos do positivismo filosófico e do determinismo econômico social. O positivismo representou a base cultural de fundo da sociedade europeia nas suas principais manifestações, incluída a filosofia, entre 1840 e a Primeira Guerra Mundial, uma fase histórica marcada por profundas mutações que se estenderam sobre cada momento da vida humana ${ }^{8}$.

A principal revolução que, nesse contexto, levou à internacionalização do mercado e da produção foi a dos meios de transporte, em primeiro lugar com a idade áurea das ferrovias e a realização de ligações antes impensáveis, como a linha de trem New York - San Francisco (símbolo da conquista do Oeste) realizada entre 1862 e 1869; a Transandina entre Chile e Argentina, acabada no ano de 1910; a Transiberiana (1891-1904) entre Moscou e Vladivostok. A aplicação das descobertas científicas na navegação favoreceu a construção de navios maiores e mais velozes, com a realização de novas rotas: em 1869 foi finalizado o Canal de Suez, que devolveu ao Mar Mediterrâneo a sua antiga centralidade como lugar de conexões entre Ocidente e Oriente; em 1859 foi realizado o Canal de Kiel, que aumentou as comunicações no Mar do Norte; em 1914 foi a vez do Canal de Panamá. Hoje se fala muito da chamada globalização, mas na verdade a maior internacionalização dos mercados ocorreu neste período histórico que antecede a Primeira Guerra Mundial ${ }^{9}$. Tudo parecia levar à unificação mundial de mercados e confins, mas na realidade política e econômica, estes são anos de protecionismo e forte competição pelo controle territorial da Ásia, África e América Latina, com um enfrentamento sempre maior entre as grandes potências ocidentais.

Como escreveu Paul Bairoch ${ }^{10}$, além da retorica liberal, a história comercial dos países desenvolvidos foi quase inteiramente uma história protecionista. Com a exceção da Inglaterra, que assumiu 
uma posição favorável ao liberalismo econômico cerca de 150 anos depois de sua Revolução Industrial, a política do laissez faire se desenvolveu apenas por dois decênios, que coincidiram com a fase mais crítica da economia no século XIX. Mediante uma articulada investigação histórico-econômica, Bairoch destruiu o mito sobre a existência real de uma idade áurea da liberdade de troca na Europa, invertendo a afirmação tradicional segundo a qual a liberdade de troca seria a regra e o protecionismo a exceção. De fato, o nível do crescimento no período de 1800-1893 foi bem menor do que os economistas afirmavam, não ultrapassando um índice médio anual de 1,5\% do PIB.

Os processos de mundialização da economia não são um fenômeno recente, mas uma tendência que atravessou em profundidade toda a fase de expansão da economia desde a Revolução Industrial e, também, de diferentes formas, as fases precedentes. A mundialização das relações sociais e produtivas burguesas é uma tendência imanente à história dessa classe intimamente revolucionária, desde a sua afirmação sobre a velha sociedade aristocrático feudal.

A ocupação colonial e o direito à expropriação das terras dos povos incivis, incapazes de frutificar as suas riquezas no sentido da civilização europeia, encontraram várias formas de legitimação na filosofia da liberdade, entre elas aquela do ícone mais venerado pela apologia liberal, o último grande filosofo que justificou e defendeu a escravidão com absoluta convicção: John Locke.

$\mathrm{Na}$ bíblia do liberalismo, O segundo tratado sobre o governo, o valor supremo da defesa da vida, conectado aos princípios de liberdade, independência e autonomia, implica o direito de dispor plenamente dos bens que o indivíduo transforma com o seu trabalho. Segundo Locke, no estado de natureza, a terra e os seus produtos são de propriedade comum de todos os homens, todavia, o indivíduo assume na sua esfera individual todas as coisas que transforma por meio do próprio trabalho.

A terra até quando fica abandonada produz poucos frutos, mas se cultivada oferece aos homens os produtos essenciais à sobrevivência deles, isso mesmo acontece com os outros bens que ele utiliza na vida cotidiana. Cada indivíduo se especializa numa determinada atividade, transformando o mundo em torno de si, portanto, a especialização e a divisão social do trabalho seriam a origem da propriedade privada e da atividade econômica do homem. O que Smith e Hegel definem como sociedade civil ou econômica. A propriedade seria a medida da capacidade empreendedora, da habilidade e da energia que cada indivíduo consegue exprimir, o uso da moeda, por sua vez, estende a propriedade além dos limites do uso pessoal e das necessidades individuais. Essa teoria é fundamento principal da teoria econômica do liberalismo depois desenvolvida por Adam Smith. A propriedade privada, exatamente porque alicerçada no trabalho, empenha toda a natureza do indivíduo encontrando uma legitimação ético religiosa como dever do homem de frutificar os bens que a natureza lhe oferece. Mas nessa maneira Locke apoia e teoriza a legitimidade também da expansão colonial inglesa e o direito de ocupar as terras que os povos “selvagens", ainda menores, não conseguem transformar em riqueza.

Com a expansão colonial e ainda mis com o industrialismo temos a extensão das relações não apenas produtivas, mas também ideológicas, da sociedade burguesa e a criação de um único mercado mundial no qual todos os outros continentes tornam-se função subalterna do crescimento econômico da Europa. Segundo Marx e Engels, na origem desse processo encontramos a premissa histórica do 
desenvolvimento da produção das manufaturas, que por sua vez levou ao esvaziamento progressivo da velha sociedade corporativo-feudal que limitava o sistema produtivo e de troca e a liberdade de iniciativa econômica. Um devir (acontecido entre 1400 e 1600) estritamente legado à estação das grandes descobertas geográficas e, por consequência, da revolução nos comércios mundiais gerada pelo afirmar-se do colonialismo. Apesar dos meios protecionistas, que cada nação sempre conservou, também nas fases mais avançadas da liberdade de troca, universalizou-se o padrão da concorrência que submeteu o comercio transformando todo os lucros em capital industrial. Isso determinou a sempre mais rápida circulação e centralização dos capitais, destruindo as velhas formas produtivas e completando a vitória das cidades sobre os campos, ou seja do capital sobre a renda fundiária. Na Ideologia Alemã esta etapa fundamental é definida como o pressuposto do terceiro período da propriedade privada, aquele da revolução industrial com a qual, por efeito da interdependência produtiva e comercial entre as nações, começa a história mundial na qual todas as relações são finalizadas às exigências da produção industrial.

No Manifesto do Partido Comunista, Marx e Engels descrevem ainda com mais capacidade de síntese o processo de internacionalização da produção, do consumo e do abastecimento das matérias-primas. Uma condição de interdependência que determina novas exigências, envolvendo também a produção imaterial, num processo que "das literaturas nacionais e locais se desenvolve para uma única literatura mundial”:

\begin{abstract}
Impelida pela necessidade de mercados sempre novos, a burguesia invade todo o globo. Necessita estabelecer-se em toda parte, explorar em toda parte, criar vínculos em toda parte. Pela exploração do mercado mundial a burguesia imprime um caráter cosmopolita à produção e ao consumo em todos os países. (...). Devido ao rápido aperfeiçoamento dos instrumentos de produção e ao constante progresso dos meios de comunicação, a burguesia arrasta para a torrente da civilização mesmo as nações mais bárbaras. Os baixos preços de seus produtos são a artilharia pesada que destrói todas as muralhas da China e obriga a capitularem os bárbaros mais tenazmente hostis aos estrangeiros. Sob pena de morte, ela obriga todas as nações a adotarem o modo burguês de produção, constrange-as a abraçar o que ela chama civilização, isto é, a se tomarem burguesas. Em uma palavra, cria um mundo à sua imagem e semelhança. ${ }^{11}$.
\end{abstract}

No terceiro volume de O Capital está indicado com mais precisão como o controle das colônias não só como destinação das mercadorias, mas como lugar para onde exportar capitais e explorar mão de obra a baixo custo - apresenta-se como uma resposta à queda tendencial da taxa de lucro. Marx assinala que a divisão dos países subdesenvolvidos entre as potências capitalistas é uma tendência destinada a aumentar exponencialmente e que ela não corresponde às velhas formas do colonialismo original, mas assume uma função avançadíssima, voltada a garantir uma nova remuneração dos capitais, indispensável para compensar aquela queda tendencial ${ }^{12}$.

Esse processo, vislumbrado já por Marx, encontra o seu máximo desenvolvimento na parte final do século XIX quando, como escreveu Lenin, o capitalismo se transformou em imperialismo.

Entre 1860 e 1870 alcança-se o apogeu da livre concorrência. Com a crise de 1873 começa a delinear-se o sistema dos cartéis. Depois, entre 1890 e 1903 (ano do começo de uma nova crise), observase um crescimento nos negócios e nas trocas que levam a uma maior concentração e centralização dos capitais. A organização por cartéis se torna a base de toda a vida econômica, e não mais um fenômeno transitório ligado a um momento da conjuntura. Ligada a essa evolução do modo de produção ocorre uma crescente contraposição internacional dos interesses nacionais. O Imperialismo de Lenin fica uma obra 
importante não apenas sobre o plano histórico-político, mas para a sua incrível atualidade, num contexto internacional sempre mais dominado pelo enfrentamento violento dos interesses nacionais que se desenvolvem ao lado da luta para o controlo das matérias primas e do fluxos financeiros-monetários. Uma pedra angular da história do pensamento político, não só na obra de desmistificação das formas de auto representação do real, mas sobretudo pelos instrumentos de luta fornecidos aos povos sujeitados e subalternos na luta pela libertação do domínio colonial na Ásia, África e América Latina. Ligada a essa evolução do modo de produção, temos uma crescente contraposição internacional dos interesses nacionais. A interpretação científica do aumento da conflitualidade entre as grandes potências capitalistas pelo domínio dos países coloniais até o estouro da primeira guerra mundial, produz um violento enfrentamento político e intelectual no começo do XX século. O primeiro trabalho que se refere às transformações nas modalidades de domínio e expansão do capitalismo é Imperialism, escrito no 1902 pelo economista John Atkinson Hobson ${ }^{13}$, depois, no 1910 o intelectual marxista Rudolf Hilferding ${ }^{14}$ editou O capital financeiro, um trabalho indispensável no percurso de análise sobre as transformações nas relações entre capital bancário e produtivo

Sinteticamente, Lênin define as características do imperialismo em cinco pontos essenciais:

1. A concentração e centralização dos capitais, levando a tendências monopolistas, com que pequenos grupos - como o sistema das boldings e das sociedades anônimas - que controlam setores produtivos inteiros.

2. A prevalência do capital financeiro sobre a produção, como resultado do estreito entrelaçamento entre capital bancário e industrial.

3. A prevalência das exportações de capitais em comparação com as exportações de mercadorias estimulando a pesquisa de áreas onde explorar a mão de obra a baixo custo, bem como de matériasprimas.

4. A divisão do mundo em áreas de influência e domínio.

5. A utilização da guerra como instrumento para obter novas repartições territoriais e a possibilidade de superação da estagnação econômica e da crise.

O eixo dessas mudanças está no que Lênin define como o sistema da participação acionaria, hoje chamado holdings, ou seja, um sistema de caixinhas chinesas ligadas à cadeia de ações com a qual, controlando o bloco acionário, se consegue controlar setores produtivos inteiros. Este sistema, escreve Lênin, favorece a manipulação, as fraudes no balanço fiscal, e isto com danos para o público, sempre em razão da irresponsabilidade das empresas-mães em relação às afiliadas. Foi o enorme desenvolvimento verificado antes da Primeira Guerra Mundial e até a crise de 1929 que favoreceu este processo doentio no interior da economia capitalista.

Em comparação com o capitalismo clássico, cuja finalidade estava na exportação de mercadoria, o capitalismo monopolista tem a tarefa de exportar capitais. No capitalismo, escreve Lênin, os lucros não são utilizados para elevar o nível de vida das massas populares no próprio país, porque o aumento dos salários levaria à diminuição dos ganhos capitalistas. O capitalismo pesquisa novas formas de remuneração do capital exportando-o para países ainda não desenvolvidos..$^{15}$ Assim, na fase de maturidade do capitalismo a exportação de capitais torna-se uma exigência fundamental para evitar a queda tendencial das taxas de lucro e para levar a efeito duas tarefas: aumentar os lucros e obter uma redução do custo do trabalho na 
pátria mãe através da concorrência do trabalho barato disponível nas colônias.

A luta pelo controle do mercado mundial leva, portanto, a divisão internacional do trabalho para a esfera de influência dos grupos monopolistas e dos Estados que encarnam os interesses deles. Mas o domínio colonial tem diferentes gradações: desde a conquista militar direta até a penetração dos capitais e a exploração exclusiva nos territórios dos Estados formalmente independentes, mas na realidade subordinados às grandes potências. E tudo isso gera uma luta sempre mais violenta entre elas.

Quanto mais o capitalismo é desenvolvido, tanto mais aguda é a concorrência, a caça às fontes de matérias-primas e a luta para a conquista das colônias. Assim o capital financeiro, em geral, faz esforços para ganhar o máximo de territórios possíveis, buscando fontes de matérias-primas com o medo de ficar para trás na luta pelo controle do último pedaço de terra ainda não dividido. ${ }^{16}$

Por isso a consequência última e a natureza mesmo do imperialismo ficam no dispositivo da guerra, porque, com a conclusão da divisão do planeta, uma nova divisão do mesmo é o único modo para sair da estagnação e da crise econômica. O desastre da Primeira Guerra Mundial, em ausência do qual é impossível imaginar o surgimento da ideologia fascista, foi a tradução concreta deste processo, numa fase em que as contradições entre as potências capitalistas não são mais passíveis de resolução. Geralmente a crise de 1929, assim como a Primeira Guerra Mundial, é apresentada como uma consequência desse tipo de desenvolvimento da economia. Mas é novamente Bairoch quem contesta essa interpretação, assim como as afirmações sobre a profundidade dessa crise. Segundo ele, os anos de 1920 não foram seguramente anos de liberdade entre as trocas comerciais, mas também não foram o apogeu do protecionismo alfandegário, e para confirmar essa assertiva basta lembrar que naquela década quase todos os países reduziram os seus próprios impostos alfandegários. Assim é que o período que precedeu a queda de 1929 foi caraterizado por políticas comerciais mais abertas e não mais fechadas, em comparação com as décadas anteriores.

Segundo Robert Gilpin ${ }^{17}$, os processos de integração da economia mundial contemporânea são na realidade irregulares e limitados a algumas frações do processo econômico, com o que se pode afirmar que o mundo atual figura na verdade menos integrado do que aquele do século XIX e até o período da Primeira Guerra Mundial. Sob o regime do Gold Standard e a influência da doutrina do laissez faire, os mercados foram mais determinantes e os governos tinham pouco poder sobre os negócios econômicos, enquanto os governos nacionais, hoje, têm mais instrumentos para gerir suas próprias economias. Concluise que a dimensão internacional do comércio, dos investimentos e dos fluxos financeiros era, portanto, mais extensa no final do século XIX do que hoje.

A transformação do capitalismo em imperialismo tem duas consequências fundamentais para o quadro que leva ao nascimento do fascismo: 1) o processo de concentração e centralização dos capitais acaba por destruir a função econômico-produtiva da pequena e média burguesia (a base social do fascismo), que, como escreve depois Gramsci, torna-se essencialmente uma classe política, especializada na intermediação, com características parasitárias; 2) o conflito permanente, para o controle mundial das áreas coloniais sob a influência das nações imperialistas, torna a potência militar o instrumento fundamental do enfrentamento político ao nível internacional e a guerra mesma uma exigência vital funcional à evolução 
social e ao progresso nacional, com funções de palingênese na ininterrupta luta entre "civilidade" e "incivilidade".

Esse segundo elemento é central no desenvolvimento do nacionalismo antes e depois da primeira guerra mundial, porque fornece a ferramenta ideológica que determina os assuntos essenciais do fascismo. Um dos seus conceitos chave é o do direito "ao espaço vital”, um princípio que faz organicamente parte da cultura política das potências ocidentais na idade do imperialismo e, mais em geral, da ideologia do colonialismo, que considera lícito dominar e explorar civilidades "inferiores" ou "primitivas". O racismo e a cientifica desumanização dos "incivis" são imanentes ao colonialismo, que se serviu das teorias sobre a existência de uma hierarquia da humanidade para legitimar o sistema criminal de dominação dos ocidentais sobre os povos coloniais.

Contrariamente às leituras que põem no mesmo plano fascismo e comunismo, até afirmar que o fascismo seria uma ideologia de esquerda, os acontecimentos russos que abalaram o mundo representaram um golpe sem precedentes às pretensões do imperialismo e, exatamente por essa razão, o fascismo se afirmou como sua negação dialética.

Nesse sentido, o assalto ao céu do outubro do 1917 é primeiramente uma revolução anticolonial. Segundo Lênin os comunistas deveriam perceber que desde o início do século XX centenas de milhões de indivíduos agiam como "fatores revolucionários autônomos ativos". Essa consciência levou a Internacional Comunista a investir recursos e energias nessas lutas, assumindo o comando de todas as questões conexas à preparação e à sustentação das lutas de libertação nacional. Esse impulso inicial e a consequente investidura de responsabilidade histórica foram fundamentais para inaugurar uma nova página na história da humanidade que levou, no curso do século XX, a maioria da população mundial à emancipação do jugo colonial.

$\mathrm{Na}$ última obra dele (O marxismo ocidental), Losurdo nos explica que a Revolução de outubro fica o grande evento da história contemporânea que não apenas favoreceu a afirmação do marxismo nas regiões periféricas, rurais e atrasadas (pensamos as revoluções na China, no Vietnam ou em Cuba). De fato, tornou o marxismo fermento vital pelas lutas de emancipação do domínio ocidental na Ásia, África, América Latina.

A história que me proponho de reconstruir começa a delinear-se entre o agosto do 1914 e o outubro do 1917, entre o estouro da primeira guerra mundial e a Revolução de Outubro. Na esteira desses acontecimentos históricos, o marxismo conheceu uma difusão planetária. (...) Inevitavelmente esse trinfo produziu uma consequência: o encontro com culturas, situações geopolíticas e condições econômico-sociais entre eles assim diferentes, estimula um processo interno de diferenciação com a emersão de contradições e conflitos antes desconhecidos ${ }^{18}$

Em antítese brutal com tudo isso, em um contexto marcado pela crise de hegemonia do velho liberalismo e a radicalização social da chamada política de massa, os fascismos surgiram reafirmando primeiramente o conceito básico do nacionalismo: "a Nação acima de tudo". Nesse sentido a sua base ideológica se encontra antes de mais nada no antissocialismo e no antibolchevismo, cujos movimentos eram considerados "forças antinacionais" porque inspiradas no princípio do internacionalismo proletário. Além 
disso, no seu nacionalismo exasperado, todos os fascismos sempre consideram o conflito social entre capital e trabalho (ponto nevrálgico da história do movimento operário em todas as suas vertentes) não só uma dialética destruidora dos interesses nacionais, mas um câncer que precisa de ser extirpado com a violência devastadora da cruzada. Nesse sentido, definir o fascismo uma ideologia de esquerda seria como dizer que o satanismo é uma religião cristã.

Agora se tornou lugar-comum citar a questionável contabilidade dos cemitérios feita no famigerado Livro negro do comunismo, no qual estão também incluídas as mortes por guerras e por carências de recursos, em grande parte dos casos provocadas de fora. Se, de fato usássemos os mesmos parâmetros adotados por Stéphane Courtois \& Co., quantos milhões de mortos devíamos atribuir à expansão mundial da chamada civilização burguesa? Vamos apenas tentar pensar: as consequências históricas da acumulação original de capital sobre as incalculáveis massas rurais expulsas dos campos transformadas em multidões de mendigos nas grandes periferias urbanas; o extermínio dos povos nativos no Norte e Sul da América, Ásia e Oceania; os mortos por causa da miséria e da exploração colonial ocidental na África, incluindo o escravismo; as infinitas guerras imperialistas conduzidas nos últimos dois séculos em todos os cantos do planeta para roubar os recursos dos "povos não civilizados". Uma hecatombe, muito bem escondida nos livros ou tratados de divulgação sobre a história da humanidade. Isso também confirma um ponto já desenvolvido por Marx e Engels na metade do século 19: justamente no terreno das ideologias é que está o verdadeiro êxito da sociedade burguesa, e assim, o fato de ter transformado o mundo em um grande cemitério é apresentado como afirmação dos princípios de liberdade e civilização ocidental sobre a barbárie dos povos primitivos. O paradoxo histórico é que, mesmo sendo mestres da ideologia, os grandes e pequenos teóricos do liberalismo fazem da crítica às ideologias a sua própria batalha mais característica. A confirmação da sua capacidade hegemônica é que a maioria das pessoas, também dotada de uma boa cultura, nela acredita e a reproduz mais ou menos conscientemente. Trata-se de problemas filosóficos, e não apenas políticos, que solicitam a compreensão da grande lição hegeliana segundo a qual "a filosofia é o próprio tempo apreendido com o pensamento"19.

Concluindo, o fascismo não pode ser expulso do terreno real da história, sendo reduzido à objetivação político-coletiva da "banalidade do mal"; o fascismo não foi um parêntese irracional, um método, nem o fruto de uma psicose que derrubou as defesas morais da civilidade europeia surgida fora do seu corpo social e da sua cultura. $\mathrm{O}$ fascismo é um movimento social e uma ideologia original historicamente determinada, o fruto de especificas condições sociais e culturais funcionais a de terminadas exigências de classe. Mas apesar das condições excepcionais que determinaram o seu aparecimento, ligadas à crise de hegemonia das classes dirigentes tradicionais na Europa da primeira metade do século XX, esse movimento representou a tentativa de instaurar a ideologia tradicional do colonialismo e do imperialismo dentro dos mesmos confins ocidentais

O fascismo é o produto das contradições objetivas e subjetivas das sociedades liberais em crise, mas também um desenvolvimento político e cultural não alheio à brutal civilização europeia que submeteu e escravizou os chamados "povos primitivos". Não reconhecer esses elos orgânicos recusando-se de historicizar premissas e causas racionais desse fenômeno, inevitavelmente, leva à utilização das categorias 
anti-históricas da teratologia, que pretendem representar a realidade como resultado inexplicável da loucura, da monstruosidade e da deformidade.

\section{Notas}

1 Doutor em filosofia pela Università degli Studi di Urbino "Carlo Bò”, docente de Filosofia Politica na Universidade Federal de Uberlancia, Presidente da International Gramsci Society - Brasil. Antonio Gramsci: "l'uomo filosofo". Appunti per una biografia intellettuale, Aipsa, Cagliari, 2019. Nas trincheiras do Ocidente. Liçoes sobre fascismo e antifascismo, UEPG editora, Ponta Grossa, Paraná, 2017. Lenin leitor de Marx, Fundação "M. Grabois"-Anita Garibaldi Editora, São Paulo, 2016. Eugenio Curiel. Il lungo viaggio contro il fascismo, Odradek, Roma, 2013. Il diavolo nell'ampolla. Antonio Gramsci, gli intellettuali e il partito. Istituto Italiano per gli Studi Filosofici, La Città del Sole, Napoli, 2005 (tese de doutorado). Lattes: http://lattes.cnpq.br/0917580148264621 Email: giannifresu@ufu.br

2 D. Losurdo, Controstoria del liberalismo, Edizioni Laterza, Roma-Bari, 2005.

3 «É ingênuo querer buscar as raízes nos superficiais e mecânicos conceitos das classes econômicas e das suas antinomias. Precisamos descer muito mais fundo, nos cérebros dos homens, e aí descobrir o mal, e só nessa dimensão tentar a cura na esperança de sair saudável» Croce, B. Scritti e discorsi politici, Laterza: Bari, 1963, p. 50.

4 «É verdade, essa [a tradição liberal do Risorgimento] tem conhecido vinte anos de uma triste, vergonhosa história; temos até visto os soldados da pátria de Mazzini e Garibaldi serem conduzidos em guerras injustas contra a França e a Grécia, ou a imitar, contra o costume e o temperamento italiano, procedimentos dos alemães nas terras da Jugoslávia: ainda temos o asco de tudo isso. Mas a Itália, por séculos e milênios, deixou uma grandíssima contribuição à civilização mundial, e não vão longe os anos no quais, com as outras nações irmãs, floresceu de vida operosa e progressiva num perfeito regime liberal, e, junto com aquelas nações irmãs, sustentou uma longa e vitoriosa guerra. O que é na nossa história um parêntese de vinte anos? E este parêntese e toda a história italiana é também história europeia e mundial». Croce, B.La libertà italiana, nella libertà del mondo, discorso tenuto al primo congresso dei partiti tenuto a Bari il 28 gennaio 1944. Edizione a cura del Partito liberale italiano: Bari, 1944.

5 Meinecke, F. La catastrofe della Germania: considerazioni e ricordi. La Nuova Italia Firenze, 1948.

6 Id. Ib. p. 87-88.

${ }^{7}$ Nolte, E. I tre volti del fascismo, Mondadori: Milano, 1971.

8 As informações históricas gerais, colocadas neste trabalho com finalidade didática, pensada para um curso de estudos universitários e acompanhar os aprofundamentos conceptuais, são o resultado de diferentes leituras de livros históricos sobre a Idade Contemporânea: AA.VV., Storia contemporanea, Roma, Donzelli, 1997; G. Sabatucci, V. Vidotto, Storia contemporanea. L'Ottocento, Laterza, Bari, 2009; G. Sabatucci, V. Vidotto, Storia contemporanea. Il Novecento, Laterza, Bari, 2009; M. Salvati, Il Novecento. Interpretazioni e bilanci, Laterza, Bari 2001; G. De Luna, La passione e la ragione. Fonti e metodi dello storico contemporaneo, La Nuova Italia, Firenze, 2001; E. J. Hobsbawm, Intervista sul nuovo secolo, Laterza, Bari 1999; E. J. Hobsbawm, Il secolo breve, Rizzoli, Milano, 1994; E. Santarelli, Il mondo contemporaneo, Editori Riuniti, Roma, 1974;

9 AA.VV., Storia contemporanea, Roma, Donzelli, 1997.

${ }^{10}$ Paul Bairoch, Economia e storia mondiale: miti e paradossi, Milano, Garzanti, 1998.

${ }^{11}$ Karl Marx, Il Manifesto del partito comunista, Editori Laterza Bari, 1999 p. 11.

12 Karl Marx, Il Capitale, Editori Riuniti Roma, 1994, III volume, p. 259- 292.

13 J. A. Hobson, L'imperialismo, (a cura di) L. Meldolesi, Istituto Editoriale Internazionale, Milano, 1974.

14 R. Hilferding, Il capitale finanziario, Feltrinelli, Milano, 1976.

${ }^{15}$ Nos séculos XIX e XX esta foi um pouco a história do Brasil, onde foi possível às grandes empresas estrangeiras explorar mão da obra e matérias-primas a baixo custo.

16 Id. Ib., p. 124.

${ }_{17}$ R. Gilpin, Attori nell'economia globale. Culture e conflitti nella globalizzarione, (org.) E. Batini, R. Ragionieri, .S. Olschki, Firenze, 2002, p. 33.

${ }_{18}$ D. Losudo, Il marxismo occidentale. Come nacque, come morì, come può rinascere, Laterza, Roma-Bari, 2017.

19 Georg W. F. Hegel, citado em Domenico Losurdo, O marxismo ocidental: como nasceu, como morreu, como pode renascer (São Paulo, Boitempo, 2018), p. 206. 